\title{
Gamification Leads to Smart Parking
}

\author{
Kavisha Duggal \\ Assistant professor \\ Raghu institute of technology \\ Visakhapatnam
}

\author{
Lovi Raj Gupta, PhD \\ Executive dean \\ lovely professional university \\ Phagwara
}

\author{
Sravani Ammu \\ Student (dept of CSE) \\ Raghu institute of technology \\ Visakhapatnam
}

\begin{abstract}
The usage of vehicles is a symbol of status these days which is indirectly leading to the urbanization of the country. Following the increase in the traffic, search for parking has become major concern now days in the cities. Searching for a parking space is a global problem which is increasing exponentially. As the global population and the number of vehicles are increasing day by day the situation is getting worse. This paper will discuss how the new technologies can be used in planning the parking efficiently and how to make it interesting for the drivers with the help of gamification.
\end{abstract}

\section{General Terms}

Parking availability, proper parking, improper parking, virtual learning.

\section{Keywords}

Smart parking, gamification, parking demand.

\section{INTRODUCTION}

India is a densely populated country where you can find people more than the free land. In such a situation yes, it is difficult to provide parking according to the demand it has got. This parking problem has become a very common matter of discussion these days. Parking is given the highest priority and has got lot of demand in the cities.

The major reason behind the increase in parking problem is the imbalance between the parking supply and parking demand i.e, the space available for parking is very less compared to the vehicle usage. The parking system plays a very important role in urban traffic system and has a close relation with accidents and environmental pollution. The most interesting fact is how parking can lead to accidents and environmental pollution:

1) In a city minimum of 700 vehicles compete for parking daily.

2) 1 day $=700$ vehicles $=23$ liters of oil consumed approximately then for 365 days???

3) It is not just a task of parking the vehicle in the slot, but the concerned person need to take it out of the slot without damaging the other's property. Few people fail to do it.

4) Due to unavailability of parking lot people sometimes park their vehicle in "NO PARKING" zone which is an illegal act.

To avoid such circumstances there is a need to have a proper planning of parking and its operations. Though it sounds very easy and simple but it isn't. There should be equal cooperation from the public to enhance the parking system.

In this paper will discuss about smart and gamified parking for maintaining and managing a proper parking system.
The concept of smart parking means that the person can prebook the parking slot for his required period of time. To make the parking experience more interesting gamification is added as an entertainment to it.

Gamification is the method of applying gaming techniques, game thinking, game designs to sign up and inspire people to achieve their goals. That is applying the gaming principles into the non-gaming activities. For example point scoring, competition with others etc to encourage the product or the service. Gamification will act as an attraction factor for the drivers to concentrate more on perfect parking. Before discussing about the smart parking and and gamification will have a look on the key issues of parking problems.

\section{KEY ISSUES OF PARKING PROBLEMS}

1) It is observed that more number of vehicles are being used these days and the space available for parking is very less leading to the increase of parking issues.

2) Another issue that leads to the parking problem is the improper usage of parking spaces. Sometimes the vehicles are parked in such a way that they use the other parking slot.

3) The other issue can be the size of the vehicle, the design and production of vehicles is done in such a way that they occupy lot of space. The size of a vehicle has become a matter of luxury and status these days. Yes they definitely indicate your status but create a lot of problem at the parking lots. These big vehicles occupy more space reducing the efficient usage of parking slots.

4) People waste so much of time in search of parking place. This may lead to the wastage of valuable time and oil. The urbanization and increase in the number of vehicles may affect the sustainability of the resources.

Keeping in mind the key issues of the parking problem the system is proposed which can solve them by using gamification and smart parking techniques.

The smart parking will make the driver tension free of parking space and gamification will help in developing the parking ability in them.

\section{SMART PARKING METHODOLOGY}

Almost everyone has experience of booking tickets for movie online where the user can find all the available seats and is allowed to pre-book their required seat. In the same way Smart parking is also a system in which people book their parking slots before going there just to save their time. An observation is made that vehicles after so much antagonism gets place for parking and later the concerned person come 
back from work it may happen that he forgets the place where he has parked the vehicle. Smart parking will help in searching and pre-booking parking slots and also phones can be used to identify the parked vehicle. Hence this smart parking system will help public in saving time that is wasted for searching and can also save the oil that is consumed while searching for the parking place.

\section{PROPOSED PARKING SYSTEM}
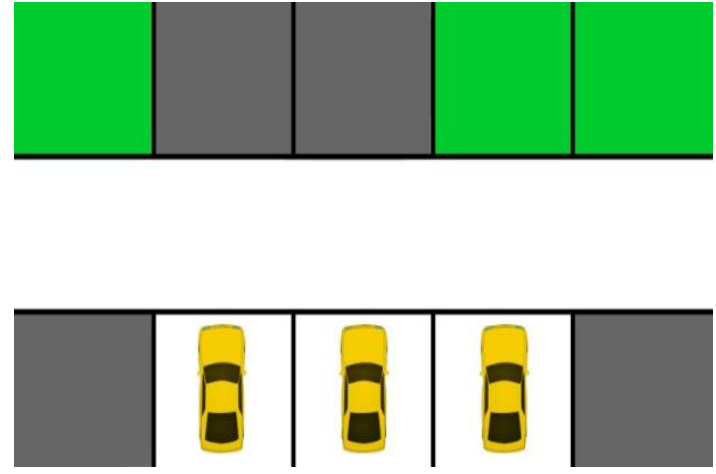

Fig 1: The availability of parking slot is displayed in such a way

Now a days when demand for parking is exponentially increasing there is a need to reserve the parking slots in malls, multiplexes, hotels etc. this need of parking slot reservation lead to an idea of smart parking. In this smart parking methodology user can select and pre-book the parking slot before going to the place. This process is almost similar to the process of booking tickets for a movie online.

\section{STEPS}

1. The user has to get registered.

2. The details provided (name, phone number, e-mail address) should be working and genuine.

3. User will be provided with a user ID and password after successful registration.

4. Once user logs into his/her account the place is to be selected i.e., the destination of the parking is to be selected by the user.

5. Once user selects the destination the available slots are displayed in the screen.

6. The available slots are represented with green color and the unavailable slots with black/grey.

7. Sensors will be placed at every parking lot that provides the user with the knowledge of availability of free parking space.

8. According to the availability of the parking lots, user has to select (or) reserve his/her desired parking lot. After selecting the desired parking lot user is requested to provide with the initial time of parking and expected parking duration

9. The parking duration would be for 4 hours, 12 hours and 24 hours. The payment is also done online.

10. Once the parking slot, initial time and parking duration is confirmed the user will get an SMS about his/her parking details.

11. The parking slot will be kept under reserved state till the user doesn't occupy it. If in any case the initial time of parking exceeds an alert message is sent to the user about the expiry of the parking slot.

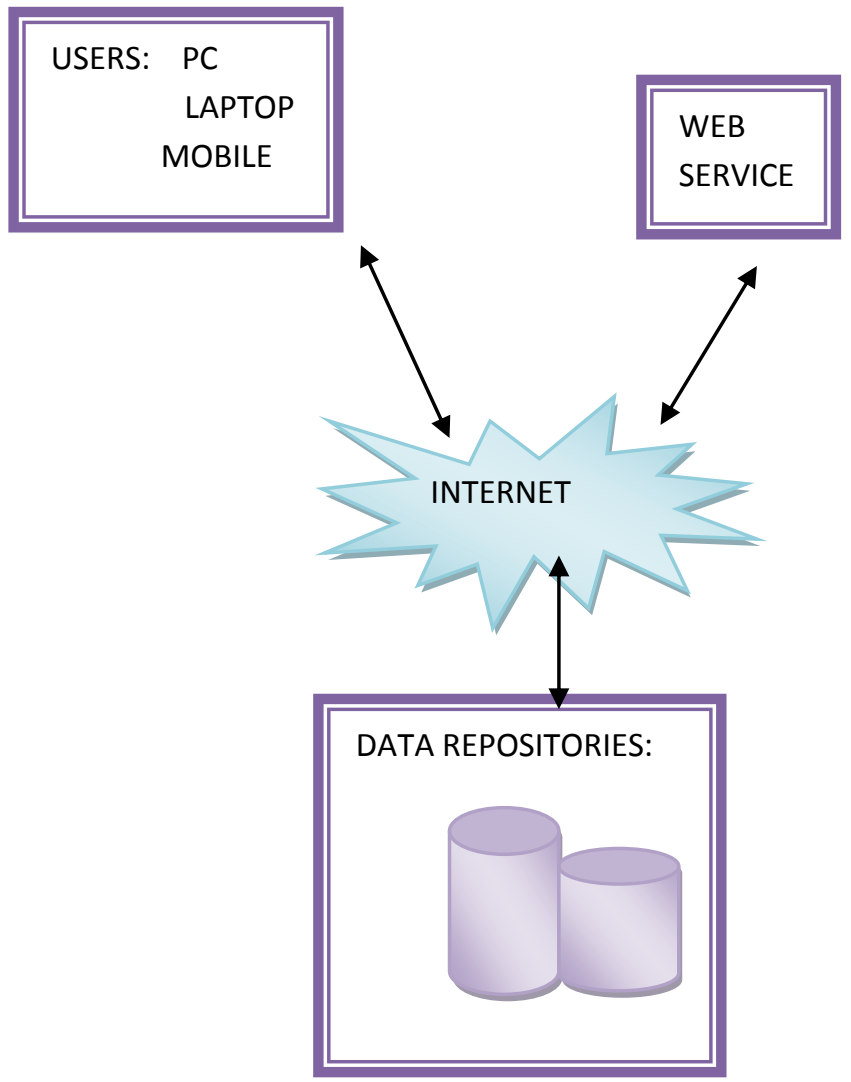

Fig 2: The working of the model.

\section{USAGE OF SENSORS}

Sensors are the devises that are used to sense the presence of any desired item. The sensors in this smart parking model are used to sense the presence of the vehicle, and also to identify whether it's a proper/improper parking. The working of sensors may be a bit difficult and expensive but is very useful for a systematic maintenance of parking.

The sensors will be connected to every parking lot which will identify the presence of the vehicle in the lot and the availability is confirmed using these sensors. There will be 2 sensors associated with each parking lot, where one sensor will identify and check for the accuracy of parking and the other is used to gain the knowledge of availability of parking lot. Once a vehicle enters the parking lot the sensors captures the vehicle and its identification number and stores it in the repository.

The sensors can also identify the proper/improper parking. The measurement of the left over place on the both sides of the vehicle parked in its lot is almost equal then it is considered as a proper parking. And if 2 different sensors identify the same vehicle in its slot then it is understood that the driver did not park the vehicle properly and is considered as improper parking. 




FIG 3: sensors attached to each parking lot.

\section{THE GAMIFIED VERSION}

As observed have seen that parking can be made smart then it can even be gamified. Some gaming thoughts and techniques can be added to make this parking process more interesting and safe. To gamify the parking process the concept is introduced for providing points to drivers. The more number of points the more will be the chances of winning. This gamified version of parking can create a process of virtual learning to the drivers who has just started their driving duty.

\section{CRITERIA FOR GAINING POINTS 8.1 Selection Of Parking Levels:}

Generally the parking in malls, multiplexes etc have multilevel parking. In this situation each level will be having some specific number of points. When the driver parks his/her vehicle in a particular parking level, he/she is added with points specified for that parking level.

Table 1: points allotted for each parking level

\begin{tabular}{|l|l|}
\hline Parking level & Points gained \\
\hline Level 1 & 2 points \\
\hline Level 2 & 3 points \\
\hline Level 3 & 5 points \\
\hline level 3 \\
\hline \\
\hline level 2 \\
\hline level 1 \\
\hline
\end{tabular}

FIG 4: The levels of parking

\subsection{Proper Parking}

After the selection of level now comes the parking position. The vehicle should be parked exactly between the separating lines. Improper parking reduces the points from the user's account.

In the below picture we can observe that the vehicle is not properly parked. Hence the points will be deducted from the past account.

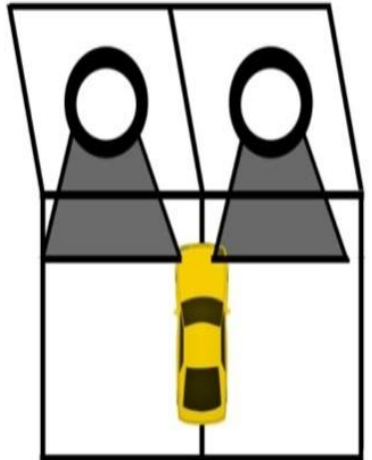

FIG 5: 2 sensors scanning the same identification number. Hence declaring it a wrong parking

In the below figure(FIG 6) we can observe that the vehicles are properly parked in the given parking lot i.e., the measurements to the sides of the vehicle is approximately equal. This parking is known as proper parking, and that particular driver is awarded with more points.

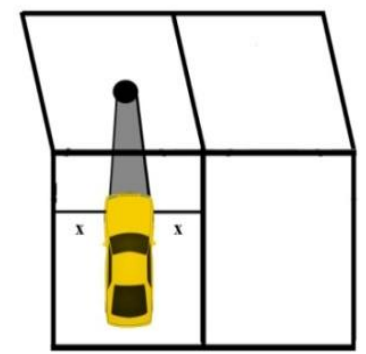

Fig 6: The sensor checks for the proper parkingof the vehicle by measuring the leftover sides.

Table 2: points allotted for proper and improper parking

\begin{tabular}{|l|l|}
\hline Position & points \\
\hline Proper & 5 points \\
\hline Improper & 3points \\
\hline
\end{tabular}

\subsection{Tracking The Driving Skills:}

In this level the driving skills of the driver is tracked and rated. The sensors connected to each parking lot will track the driving skills of the driver. The sensors will scan the identification number of the vehicle and that will be stored in the database connected. The horizontal sensor keeps track of the total time taken for the driver to park the vehicle and also concentrates on the position of parking. Points are awarded according to the parking position and parking time.

" The more faster and the more proper you park, the more points you gain". 


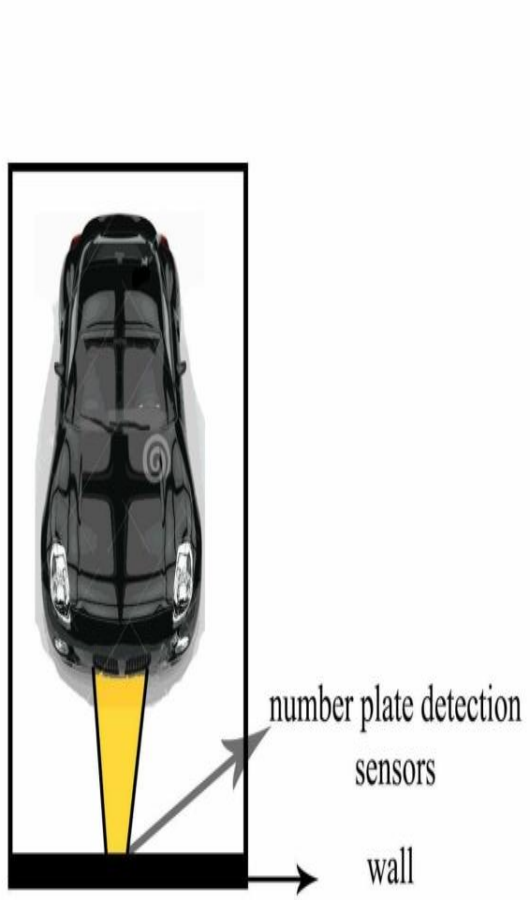

Fig 7: the sensor on the wall scans the identification number of the vehicle

Table 3: Points allotted according to the time taken

\begin{tabular}{|l|l|}
\hline Time taken for parking & Points awarded \\
\hline$<2$ minutes & 10 points \\
\hline $2-5$ minutes & 8 points \\
\hline$>5$ minutes & 5 points \\
\hline
\end{tabular}

\section{USER GAME CARD}

User is provided with a game card that will resemble the ATM, Debit cards etc. The card will hold all the details of the driver. The points scored by the drivers in the process of parking the vehicle, will all be added into the user account. The sensors when scans for the identification number is connected to the database. The scanned identification number is searched in the database, and if is available then the points scored will be added to the previous one. Otherwise a new record is created.

After a specific period of time the user with highest number of points will be awarded as the skillful driver.



FIG 8: The sample gaming card provided to the user.

\section{CONCLUSION}

After discussing about the present problems of parking and the gamified solution for it we can come to a conclusion that the smart parking will eliminate the problem of searching for parking lot in private places. This smart parking is integrated with gaming techniques to make the parking experience of drivers more interesting. The introduction of points into the parking process will motivate people to park their vehicles in a systematic way and will eliminate the problem of wrong parking. This methodology is so efficient that it can be implemented in railway stations, airports, public parking lots etc., In the near future. Have a great experience of smart and gamified parking..!!

\section{REFERENCES}

[1] Android based smart parking system using slot allocations and reservations, Renuka $\mathrm{R}$. and $\mathrm{S}$. Dhanalakshmi, ARPN journal of engineering and applied sciences. Vol 10, no. 7 , April 2015.

[2] A reservation based parking system, Hongwei Wang* and Wenbo He $\uparrow *$ Department of Computer Science \& Engineering, University of Nebraska-Lincoln, NE, USA,

[3] Challenges of implementing gamification for behavior change: lessons learned from the design of blues budies, valantina rao. CMI'13 april 27 - may 272013 paris, france

[4] Gamified approach to database normalization, Kavisha Duggal, Anukul Srivatsav, Satvinder Kaur, International Journal of Computer Applications (0975 - 8887) Volume 93 - No 4, May 2014

[5] Innovative parking programs across U.S

[6] Smart parking, by Aditya Basu ,happiest minds technologies PVT. LTD.

[7] Smart parking system using wireless sensor networks, Joseph Jeffrey, Roshan Gajanan Patil, Skanda Kumar Kaipu Narahari, Yogish Didagi, Jyotsna Bapat, Debabrata Das International Institute of Information Technology, Bangalore, SENSORCOMM 2012 : The Sixth International Conference on Sensor Technologies and Applications 
[8] Smart parking system with image processing facility, M.O. Reza, M.F. Ismail*, A.A. Rokoni, M.A.R. Sarkar Department of Mechanical Engineering, Bangladesh University of Engineering \& Technology (BUET), Dhaka, Bangladesh , I.J. Intelligent Systems and Applications, 2012, 3, 41-47 Published Online April 2012 in MECS (http://www.mecs-press.org/) DOI: 10.5815/ijisa.2012.03.06 Copyright (C) 2012 MECS I.J. Intelligent Systems and Applications, 2012, 3, 41-47.

[9] Using gamification to incentivize sustainable urban mobility, raman khazamiakin, Luca Piras, Fransico Avesani.

[10] Why parking matters? , Ray Lahood, Internation Parking Institute(IPI) 